\title{
Outcomes of Integrated Behavioral Health with Primary Care
}

\author{
Bijal A. Balasubramanian, MBBS, PhD, Deborah J. Cohen, PhD, \\ Katelyn K. Jetelina, MPH, PhD, L. Miriam Dickinson, PhD, Melinda Davis, PhD, \\ Rose Gunn, MA, Kris Gowen, PhD, Frank V. deGruy III, MD, MSFM, \\ Benjamin F. Miller, PsyD, and Larry A. Green, MD
}

Background: Integrating behavioral health and primary care is beneficial to patients and health systems. However, for integration to be widely adopted, studies demonstrating its benefits in community practices are needed. The objective of this study was to evaluate effect of integrated care, adapted to local contexts, on depression severity and patients' experience of care.

Methods: This study used a convergent mixed-methods design, merging findings from a quasi-experimental study with patient interviews conducted as part of Advancing Care Together, a community demonstration project that created an innovation incubator for practices implementing evidence-based integration strategies. The study included 475 patients with a 9-item Patient Health Questionnaire (PHQ-9) score $\geq 10$ at baseline, from 5 practices.

Results: Statistically significant reductions in mean PHQ-9 scores were observed in all practices, ranging from 2.72 to 6.46 points. Clinically, $50 \%$ of patients had $\mathrm{a} \geq 5$-point reduction in PHQ-9 score and $32 \%$ had a $\geq 50 \%$ reduction. This finding was corroborated by patient interviews that demonstrated positive experiences with behavioral health clinicians and acquiring new skills to cope with adverse situations at work and home.

Conclusions: Integrating behavioral health and primary care, when adapted to fit into community practices, reduced depression severity and enhanced patients' experience of care. Integration is a worthwhile investment; clinical leaders, policymakers, and payers should support integration in their communities. (J Am Board Fam Med 2017;30:130-139.)

Keywords: Behavioral Medicine, Community Health Services, Depression, Integrated Health Care Systems, Primary Health Care, Surveys and Questionnaires

Compelling evidence from randomized trials supports the integration of behavioral health care and primary care in improving health outcomes, the

This article was externally peer reviewed.

Submitted 21 July 2016; revised 4 January 2017; accepted 9 January 2017.

From the Department of Epidemiology, Human Genetics and Environmental Sciences, University of Texas School of Public Health, Dallas, TX (BAB, KKJ); the Department of Family Medicine, Oregon Health and Science University, Portland (DJC, MD, RG, KG); and the Department of Family Medicine, University of Colorado School of Medicine, Denver (LMD, FVdG, BFM, LAG).

Funding: This research was supported by a grant from the Colorado Health Foundation (CHF-3848).

Conflict of interest: none declared.

Corresponding author: Bijal A. Balasubramanian, MBBS, PhD, Department of Epidemiology, Human Genetics and Environmental Sciences, University of Texas School of Public Health, Dallas Regional Campus, 6011 Harry Hines Blvd., V.8.112, Dallas, TX 75390 (E-mail: bijal.a.balasubramanian@uth.tmc.edu). experience of health care, and costs. ${ }^{1-11}$ Behavioral health care, in this context, encompasses care for mental disorders, substance use problems, psychosocial and family problems, and health behavior change. ${ }^{12,13}$ However, the adoption of integrated care $^{14}$ has been slow because of challenges implementing it in community settings, and relatively little research is available on context-specific implementation strategies. ${ }^{15-17}$

We previously documented the extensive processes used by diverse community mental health centers and primary care practices to integrate behavioral and primary care in the Advancing Care Together (ACT) demonstration project. ${ }^{15,16,18-27}$ The ACT evaluation showed that the shift to integrated care requires extensive health system redesign, including modifications to team composition, ${ }^{19,28}$ operations, ${ }^{19,22}$ use of physical space, ${ }^{21}$ 
and interprofessional interaction, ${ }^{19}$ and that variations in approaches have implications for the cost of the health system redesign ${ }^{29}$ and how well these efforts actually reach target patients. ${ }^{30}$ This body of work established clear and compelling evidence that community practices modify evidence-based integration approaches to fit their local context. ${ }^{15}$ However, little evidence demonstrates whether such locally adapted approaches are associated with improving patient outcomes in community settings. Therefore, among 5 ACT practices that used the 9-item Patient Health Questionnaire (PHQ-9) as a common measure of depression severity, ${ }^{31}$ we sought answers to 2 questions: (1) Were locally developed, unrestricted, and uncontrolled integration innovations associated with improvements in depression severity? (2) What were patients' experiences of integrated care delivered via these community approaches?

\section{Methods}

This article reports on analyses from ACT, a Colorado integrated care demonstration project supported by the Colorado Health Foundation. The project was conducted over a 4-year period, from 2011 to 2015. The methods have been presented previously in detail. ${ }^{16} \mathrm{~A}$ mixed-methods learning evaluation ${ }^{30}$ generated key practice-based findings demonstrating how ACT practices implemented integrated care in the context of usual care delivery. The study received ethical approval by the institutional review boards of the Oregon Health \& Science University, University of Texas Health Science Center at Houston, and University of Colorado. Specifics of the evaluation design, practice interventions, data collected, and analyses are described elsewhere. ${ }^{30}$ For this study, we used an interactive, convergent, mixed-methods design, ${ }^{32}$ using quantitative data to evaluate change in a standardized, clinical outcome (PHQ-9 score) and to develop a sampling frame for qualitative interviews, and using qualitative data to characterize patients' experiences with integrated care.

\section{Practice Sample}

Eleven Colorado practices were selected by an external steering committee for participation in ACT. Practices varied with regard to type (primary care or mental health clinic), size, and ownership. Practices were not incented financially to integrate care (they received technical support and $\$ 50,000$ per year to offset evaluation costs), nor were they told how to integrate- each adopted an evidence-based strategy particularly suited to their setting. For the quantitative analysis, we included 5 practices $(2 \mathrm{com}$ munity mental health centers [CMHCs] and 3 primary care practices) that all used the PHQ-9 to screen and monitor patients for depression and were able to report patient-level data from their electronic health records (EHRs). Practices were excluded if they did not provide patient-level data $(\mathrm{n}=3)$, used screening strategies that could not be aligned with other measures $(n=2)$, or focused exclusively on pregnant patients $(n=1)$. Table 1 describes key features of the 5 practices included in this analysis and the evidence-based integration strategies they implemented. Patients participating in qualitative, in-depth interviews to characterize their experience of integrated care were selected from 4 of the 5 practices included in the quantitative analysis.

\section{Patient Sample}

The patient sample for this study was derived from patient tracking sheets maintained by participating practices. ${ }^{30}$ This tracking sheet documented patients who were screened with the PHQ-9, those who screened positive, and receipt of integrated care services. For this study, we included patients who screened positive on the PHQ-9, defined as a PHQ-9 score $\geq 10$. A PHQ-9 cutoff of $\geq 10$ has been shown to be $88 \%$ sensitive and $88 \%$ specific for the diagnosis of major depression. ${ }^{31}$ Patient tracking sheets also served as the sampling frame to select patients for in-depth qualitative interviews. Patient selection purposively varied on demographic characteristics (ie, age, race/ethnicity, and sex) and on the level of exposure to practices' integrated care interventions. A total of 47 patients across 4 practices agreed to be contacted for interviews, and 25 were interviewed in person $(n=8)$ or by phone $(n=17)$ to accommodate patient preferences and availability. $\mathrm{Pa}-$ tients who agreed to be contacted but were not interviewed declined participation at time of contact, did not return or answer calls, or did not show at the time of interview.

\section{Measures}

The main quantitative outcome measure was change in PHQ-9 score from baseline. Secondary outcomes included the proportion of patients with a 50\% reduction in PHQ-9 score and with a reduction $\geq 5$ points on the PHQ-9. ${ }^{31,33,34}$ Patient 
Table 1. Practice Characteristics and Description of Integrated Care Approach Implemented at Each Advancing Care Together Practice

\begin{tabular}{|c|c|c|c|c|}
\hline $\begin{array}{l}\text { Practice } \\
\text { ID }\end{array}$ & $\begin{array}{l}\text { Practice } \\
\text { Type }\end{array}$ & Setting & Ownership & Integrated Care Approach \\
\hline 1 & Primary care & Suburban & Clinician & $\begin{array}{l}\text { - Primary care practice partnered with a CMHC } \\
\text { to hire a BHC and also expanded health- } \\
\text { coaching services } \\
\text { - Systematically screened patients in the waiting } \\
\text { room for medical and behavioral conditions } \\
\text { - Provided brief and intensive BH counseling } \\
\text { and health coaching in the practice }\end{array}$ \\
\hline 2 & Primary care & Suburban & Clinician & $\begin{array}{l}\text { - Primary care practice affiliated with multiple } \\
\text { primary care practices in the region; the BHC } \\
\text { hired to serve patients across these practices is } \\
\text { colocated in some practices but not others. } \\
\text { - Front desk staff systematically screened } \\
\text { patients using a Web-enabled tablet to identify } \\
\text { BH needs. } \\
\text { - BHC provided traditional therapy. Patients in } \\
\text { need of more intensive mental health and } \\
\text { substance use services were referred out. }\end{array}$ \\
\hline 3 & CMHC & Rural & Private, not for profit & $\begin{array}{l}\text { - Primary care team (PCP/MA team) and a } \\
\text { BHC were embedded in this CMHC to } \\
\text { provide primary care and } \mathrm{BH} \text { services to all } \\
\text { patients. } \\
\text { - Systematically screened patients in the waiting } \\
\text { room for medical and } \mathrm{BH} \text { conditions. } \\
\text { - Provided brief and intensive } \mathrm{BH} \text { counseling } \\
\text { and primary care in the practice. }\end{array}$ \\
\hline 4 & Primary care & Urban & Clinician & $\begin{array}{l}\text { - Private primary care practice expanded their } \\
\text { partnership with a private mental health } \\
\text { agency to provide integrated care. } \\
\text { - Screened patients with diabetes and } \\
\text { hypertension for depression. } \\
\text { - BHCs provided brief counseling and referred } \\
\text { patients to a partnering mental health agency } \\
\text { for intensive counseling. }\end{array}$ \\
\hline 5 & CMHC & Suburban & Private, not for profit & $\begin{array}{l}\text { - CMHC hired PA and MA team to serve its } \\
\text { patients and to expand its services to a non- } \\
\text { SPMI population. } \\
\text { - Systematically screened patients to identify } \\
\text { physical and BH needs among those without a } \\
\text { PCP. } \\
\text { - The PA, health navigator, or health coach } \\
\text { treats patients who are identified with mild to } \\
\text { moderate BH needs and who are seeing the } \\
\text { primary care team, whereas therapists in the } \\
\text { clinic treat patients with SPMI and substance } \\
\text { use needs. }\end{array}$ \\
\hline
\end{tabular}

BH, behavioral health; BHC, behavioral health clinician; CMHC, community mental health center; MA, medical assistant; PA, physician assistant; PCP, primary care physician; SPMI, serious and persistent mental illness.

experience of integrated care, assessed from patient interviews, was the main qualitative outcome.

\section{Data Collection and Management}

Practices used a standardized protocol to extract clinical data from EHRs. Visit-level data for a minimum of 18 months from baseline were collected; these included sociodemographic variables (age, sex, race/ethnicity, and insurance), dates of visits, dates and scores of PHQ-9, and the presence of specific chronic diseases (diabetes, hypertension, thyroid disease, heart disease, asthma, and cancer) from EHR problem lists.

Interviews were conducted in the patient's primary language: 2 were conducted in Spanish and the rest were in English. We discarded 1 interview 
because of poor audio quality, leaving 24 interviews for analysis. Importantly, interviewers were blinded to the quantitative results and to individual patient change in PHQ-9 to minimize bias. We used a semistructured interview guide that was field tested and refined. Interviews were audio-recorded and professionally transcribed. Transcripts were checked for accuracy, deidentified, and transferred data to Atlas.ti version 7 (Scientific Software Development $\mathrm{GmbH}$, Berlin, Germany) for data management and analysis.

\section{Analyses}

Statistical analyses were conducted for each practice separately. Descriptive statistics characterized the patient sample and mixed effects linear regression models estimated change in PHQ-9 score between the baseline visit and the last visit after the intervention. Models were adjusted for sex, age, race/ethnicity, insurance type, and comorbidity. We also estimated change in PHQ-9 score every 6 months by constructing random coefficient growth-curve models (random intercepts, random slopes) that included a term for the number of months from baseline for every available visit. ${ }^{35}$ Finally, we examined potential modifying effects of comorbidity by including an interaction term in both models. All analyses were conducted using SAS software version 9.4 (SAS Institute Inc., Cary, NC).

We analyzed patient interview data to understand how patients perceived the benefits and drawbacks of integrated care. Data were analyzed using an immersion-crystallization approach. ${ }^{36,37}$ This was done in 3 steps. First, as a group, we listened to each patient interview and analyzed it while reviewing transcripts to identify and code patterns or themes. Second, we analyzed how emerging find- ings manifested across patients, noting patterns in the observed breadth of need and severity that emerged in patient stories, as well as variations in care experiences. Third, we explored in more detail how patients described the benefits and drawbacks of integrated care.

Qualitative and quantitative analyses were first conducted independently to ensure unbiased interpretation. After completing analyses, qualitative and quantitative findings were integrated together using the "merging" approach described by Fetters et al. ${ }^{32}$

\section{Results}

Across the 5 ACT practices, we examined the effect of integrated care on change in PHQ-9 among 475 patients who had a PHQ-9 score $\geq 10$ and at least 2 visits between 2012 and 2013. Three of the 5 practices reached $>90 \%$ of patients eligible for screening over a 3-month period (Table 2). Of these patients, 25 were sampled for in-depth interviews during 2013 to 2014 to characterize their experience of integrated care.

\section{Effect of Integrated Care Strategies on Change in PHQ-9}

Table 3 characterizes the patient sample, which was predominately female $(69.3 \%)$, non-Hispanic white $(83.2 \%)$, and had private/commercial insurance (41.5\%). Mean age was 43.9 years (standard deviation, 14.2 years). Hypertension was the most prevalent comorbidity, followed by asthma.

Table 4 presents the effects of integrated care strategies on change in PHQ-9. Across practices, patients' spent an average of 6 to 9 months in the cohort. The average number of visits per patient ranged from 2.3 to 3.6 visits. When examining

Table 2. Patient Eligibility for Study and Analysis

\begin{tabular}{|c|c|c|c|c|}
\hline Practice ID & $\begin{array}{c}\text { Screening } \\
\operatorname{REACH}^{23}(\%)^{*}\end{array}$ & $\begin{array}{l}\text { Patients Who Screened } \\
\text { Positive for ACT } \\
\text { Intervention (n) }\end{array}$ & $\begin{array}{l}\text { Patients with a PHQ-9 Score } \\
\geq 10 \text { at Baseline (n) }\end{array}$ & $\begin{array}{l}\text { Patients with a PHQ- } \\
\text { Score } \geq 10 \text { at Baseline } \\
\text { and }>1 \text { Visit (n) }\end{array}$ \\
\hline 1 & 90.0 & 675 & 181 & 104 \\
\hline 2 & 91.0 & 842 & 372 & 103 \\
\hline 3 & 90.0 & 539 & 224 & 179 \\
\hline 4 & 12.1 & 80 & 77 & 24 \\
\hline 5 & 2.2 & 716 & 323 & 65 \\
\hline
\end{tabular}

*Screening REACH is defined as the percentage of target patients who were assessed for integrated care over a 3-month period. ACT, Advancing Care Together; PHQ-9, 9-item Patient Health Questionnaire. 
Table 3. Characteristics of Patients with a 9-Item Patient Health Questionnaire Score $\geq 10$

\begin{tabular}{lc}
\hline & Patients $(\mathrm{n}=475)$ \\
\hline Male sex* $^{*}$ & $146(30.7)$ \\
Age (years), mean (SD) & $43.9(14.2)$ \\
Race/ethnicity ${ }^{\dagger}$ & \\
Non-Hispanic white & $366(83.2)$ \\
Non-Hispanic black & $6(1.4)$ \\
Hispanic & $50(11.4)$ \\
Other & $18(4.1)$ \\
Insurance type & \\
Private/commercial & $149(31.4)$ \\
Medicare & $57(12.0)$ \\
Medicaid & $104(21.9)$ \\
Self-pay & $49(10.3)$ \\
Unknown & $116(24.4)$ \\
Comorbidities & \\
Cancer & $10(2.1)$ \\
Diabetes & $70(14.7)$ \\
Hypertension & $111(23.4)$ \\
Heart disease & $46(9.7)$ \\
Thyroid & $80(16.8)$ \\
Asthma & $89(18.7)$ \\
\hline
\end{tabular}

Data are $\mathrm{n}(\%)$ unless otherwise indicated.

${ }^{*} 0.2 \%$ missing.

${ }^{+} 7.4 \%$ missing.

change in adjusted mean PHQ-9, all practices showed a statistically significant decrease ranging from 6 points (standard error, 0.7; practice 1) to about 3 points (standard error, 0.7; practice 5). Growth-curve models also demonstrated significant decreases in PHQ-9 over 6 months for all practices. Patients of primary care practices showed larger decreases in PHQ-9 than those of CMHCs. The presence of common chronic conditions did not modify the effect of integrated care on PHQ-9 change at any of the practices (data not shown).

When examining the percentage of patients who experienced clinically meaningful improvements in PHQ-9 (Figure 1), overall half had a $\geq 5$-point PHQ-9 score reduction (range, 38-61\%), and a third had at least a $50 \%$ score reduction (range, $17-45 \%)$. Similar to changes observed in mean PHQ-9, a higher percentage of patients of primary care practices demonstrated improvement in PHQ-9 compared with patients at CMHCs.

\section{Patients' Experiences with Integration}

Of 25 patients interviewed from 4 ACT practices, mean age was 50 years (standard deviation, 16.5 years); $67 \%$ were female, $71 \%$ were white, and $17 \%$ were Hispanic. Most patients reported positive experiences with integrated care in both primary care practices and CMHCs.

The majority of interviewed patients receiving integrated care reported that having the behavioral health clinician (BHC) and primary care clinician as part of the same team and under the same roof was beneficial; they appreciated the care they received, and that their clinicians were working and talking with each other. A small number of patients reported neutral to negative reactions to integrated care: dissatisfaction with a clinician for refusing to prescribe controlled medication for pain; dissatis-

Table 4. Effect of Implementing Integrated Care Strategies on Mean Change in the 9-Item Patient Health Questionnaire for Patients Receiving Care in Advancing Care Together Practices

\begin{tabular}{|c|c|c|c|c|c|c|c|c|}
\hline \multirow{2}{*}{$\begin{array}{l}\text { Practice } \\
\text { ID }\end{array}$} & \multirow[b]{2}{*}{ Patients (n) } & \multirow{2}{*}{$\begin{array}{l}\text { Months in the } \\
\text { Study, Mean } \\
\text { (SD) }\end{array}$} & \multirow{2}{*}{$\begin{array}{l}\text { No. of Visits, } \\
\text { Mean (SD) }\end{array}$} & \multicolumn{2}{|c|}{$\begin{array}{c}\text { PHQ-9 Score, Mean } \\
\text { (SD) }\end{array}$} & \multicolumn{2}{|c|}{$\begin{array}{l}\text { Before/After Change in } \\
\text { PHQ-9 Score, Mean (SE) }\end{array}$} & \multirow{2}{*}{$\begin{array}{c}\text { Adjusted }^{+} \text {Change } \\
\text { in PHQ-9 Score } \\
\text { over } 6 \text { Months, } \\
\text { Mean (SE) }\end{array}$} \\
\hline & & & & Baseline & After & Unadjusted & Adjusted* & \\
\hline 1 & 104 & $6.49(4.6)$ & $3.46(2.6)$ & $17.20(4.1)$ & $10.34(7.1)$ & $-6.87(0.7)^{\dagger}$ & $-6.46(0.7)^{\dagger}$ & $-3.19(0.6)^{\dagger}$ \\
\hline 2 & 103 & $7.41(4.7)$ & $2.87(1.8)$ & $16.19(4.3)$ & $10.58(8.3)$ & $-5.61(0.8)^{\dagger}$ & $-4.97(1.1)^{\dagger}$ & $-3.25(1.1)^{\dagger}$ \\
\hline 3 & 179 & $8.49(4.6)$ & 3.55 (1.6) & $17.02(4.3)$ & $12.72(6.8)$ & $-4.30(0.5)^{\dagger}$ & $-3.89(0.5)^{\dagger}$ & $-2.03(0.4)^{\dagger}$ \\
\hline 4 & 24 & $9.26(3.7)$ & $2.31(0.5)$ & $18.20(3.1)$ & $14.15(4.2)$ & $-4.06(1.3)^{\dagger}$ & $-4.47(1.5)^{\dagger}$ & $-3.12(1.2)^{\ddagger}$ \\
\hline 5 & 65 & $6.20(4.1)$ & $2.82(1.1)$ & $18.06(4.2)$ & $15.09(6.4)$ & $-2.97(0.8)^{\dagger}$ & $-2.72(0.7)^{\dagger}$ & $-1.50(0.5)^{\S}$ \\
\hline
\end{tabular}

*Adjusted for race (non-Hispanic white, non-Hispanic black, Hispanic, other), age (continuous), payer source (private, Medicare, Medicaid, self-pay, other), and sex.

${ }^{\dagger} P<.001$.

${ }^{\circledR} P<.01$.

${ }^{\ddagger} P<.05$.

SD, standard deviation; SE, standard error; PHQ-9, 9-item Patient Health Questionnaire. 
Figure 1. Clinically relevant change in the 9-item Patient Health Questionnaire score for patients receiving care among Advancing Care Together (ACT) practices.

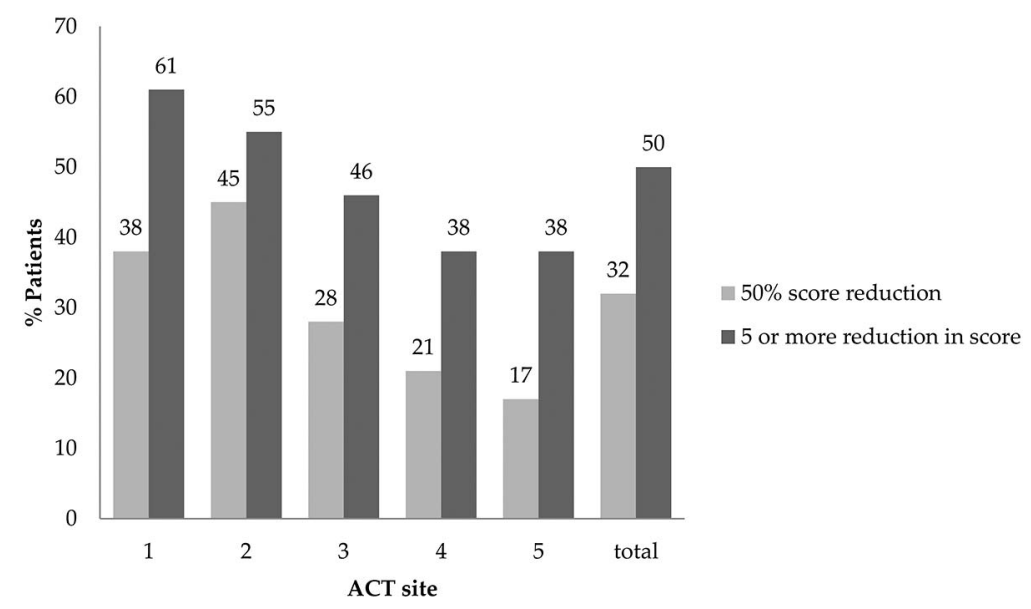

faction with a therapist who discharged the patient from a dialectical behavior therapy group following several missed sessions; and misalignment with the $\mathrm{BHC}$ because of perceived age differences ("she went to school with my kid") or parenting philosophy (therapist had a "different view on teenagers than what I had").

Patients in the CMHC setting reported that they valued the assistance they and their family members received with medical issues, health behavior change, and social support. As 1 patient reported, her son was the reason for initiating care at the CMHC. As can happen when a child is ill, the mother experienced emotional distress, and the clinicians at the CMHC were able to help with her and her family with their medical and behavioral health needs: "I kind of had a nervous breakdown because of everything that had happened.... I have been struggling with some other health issues. I have been diagnosed with [chronic obstructive pulmonary disease] and have some really serious cholesterol problems. I totally had to change my diet-my way of living. I quit smoking . . . I see those people several times a week.... With a lot of therapy, some medication, not for all us, but for some of us, a lifestyle change . . . we actually are functional people, not just together, but individually" (patient 1 , practice 3 ).

CMHC patients also reported that primary care clinicians played a valuable role in managing their behavioral health: "They really helped me-super helped me when my son passed away. [The physician assistant (PA)] is the 1 that handled me during that time and she done just fabulous..." (patient 2, practice 5). The PA helped this patient in a number of ways, 1 of which was to connect her with a grief support group.

In the primary care setting, patients valued the action and solution-oriented approach BHCs used to help them cope with common problems, such as managing anger, grief, and relationships. The following excerpt illustrates how a BHC helped a patient manage frustration toward her husband, who was not, in her opinion, dealing well with his own medical conditions: "I came in 1 day [to see the $\mathrm{BHC}$ ] and I was totally beside myself. Just in tears and just ranting and raving. By the time I had seen her 3 weeks I was fine. . . I took a lot away from my meetings with her. I have a couple of friends I talk with-1's in Wisconsin. I'd go home and I'd call her. I'd say, 'This is what she said. I did this and I did that.' . . . Yeah. It worked really, really well ..." (patient 3, practice 4).

Patients also valued how BHCs helped patients reframe how they viewed events, themselves, and others, and this helped them manage important relationships. For example, 1 patient reported that a BHC helped her manage her relationship with her grandchildren, despite her feelings of resentment and of being taken advantage of by her daughter-in-law: "She [the BHC] said for me to find that comfort place with the grandkids .... She is the 1 that helped me with that really bad.... She taught me how to put the grandkids first and take them to the park. And what time I do have them, just enjoy them right away ... I do not know when I am going to see them again or what is going to 
happen. But they always end up coming here anyways to Grandma's" (patient 4, practice 1).

We heard from patients that these skills were also applied to managing emotions and relationships in the workplace.

Patients received different levels of exposure to behavioral health care in the primary care setting, with some patients receiving 1 session, others receiving 3, and a few patients working with BHCs intermittently, as needed, or regularly over the course of a year. The example above shows how just 1 counseling session with a BHC can be helpful to a patient. The example below shows how patients may engaged the BHC intermittently and as needed to prepare for surgery ("I know I need go in and see her preop ... she helps me to slow down and not have as huge expectation and disappointment in myself"), and to cope with life stresses, such as a spouse losing his job:

[The doctor] suggested it the first time. [My husband] had lost his job back then and he hadn't gotten a new job yet. There was financial stress too. ... She [the BHC] looks at you like she's really listening ... and she's trying to figure out something to help you.... She really tries to give you information of what she has heard or knows or learned that might help, suggestions and all. . . I nearly always come away from here with 1 thing at least and that 1 thing can make all the difference. . . It'll pop up in your mind at a weird time, something that we talked about. It'll make me relax inside a little bit and say 'okay, I am really expecting too much of myself right now"' (patient 5, practice 1$)$.

Patients reported that BHCs listened and helped them find new solutions that they could act on to manage common life stressors, events. and problems. BHCs helped them recognize when they needed to reengage the $\mathrm{BHC}$.

\section{Discussion}

Prior research on integrated behavioral health and primary care has focused on efficacy or effectiveness studies conducted under research-driven experimental conditions where homogeneity between practices and tight control are desired. In our previous work, we showed that community practices adopting integrated care modify evidence-based strategies to fit their local context. ${ }^{15,16,18-22}$ This study extends our previous research by demonstrating that among community practices implementing integrated care strategies relevant to their local setting and context, depression severity improved and patients perceived tangible benefits of integrated care.

$\mathrm{CMHC}$ and primary care practices differed in the magnitude of PHQ-9 change and in experiences of care. CMHC practices cared mostly for patients with serious and persistent mental illnesses and focused on integrating medical and substance use care. All the primary care practices, on the other hand, focused on managing depression in the context of providing whole-person care. This may explain the marginally smaller reduction observed in PHQ-9 among CMHCs. Yet, why did PHQ-9 scores change at all in the CMHC setting? Patient interview data might hold the answer: when behavioral health needs surfaced in CMHCs, the primary care clinician addressed these needs by, for example, briefly counseling patients in the course of medical care and making connections with additional services (eg, therapy group).

Evaluation of demonstration studies requires special appreciation. Such evaluations are complex and multilevel, and practices, while working toward a common target, are innovating in distinctive ways to accomplish their goals. The standards for randomized controlled studies (eg, fidelity, randomization, control) are often infeasible to apply in these situations. Flexibility and adaptability are called for. ${ }^{38}$

It is in this context that the following study limitations should be recognized. First, this was a quasi-experimental study. We anticipated design limitations as a result of a lack of control groups and therefore collected and analyzed multiple types of data (practice surveys, EHR data, and practice staff and patient interviews) with the goal of triangulating qualitative and quantitative results, ${ }^{30,39,40}$ as presented in this article. Future studies would benefit from comparison groups to further enhance internal validity. Second, because outcomes were measured during the course of usual care and not at prespecified time points, it is possible that patients with less severe depression may not have returned for follow-up because they experienced improvements without intervention. Upon reanalyzing data in sensitivity analyses, assuming no change in PHQ-9 for patients without follow-up visits, over- 
all reductions in PHQ-9 remained statistically significant (data not shown). Further, measuring outcomes during the usual course of care allowed us to examine change in PHQ-9 over a longer follow-up time period (6-9 months) than what is commonly prespecified in most research trials (6-12 weeks). ${ }^{41-44}$ Third, the before-and-after study design limits our ability to differentiate whether observed changes in PHQ-9 are better than usual care. ${ }^{45-47}$ However, we found that the approaches implemented by ACT practices resulted in $50 \%$ of patients experiencing at least a 5 -point reduction in PHQ9 (range across practices, 38-61\%). This level of reduction is considered to be clinically meaningful and beneficial, ${ }^{48}$ especially when observed among patients seen in busy community practices integrating care. At the very least, it suggests that implementing integrated care in community practices did not negatively affect outcomes. Fourth, ACT was not a study designed to improve depression care. Although practices focused their integration efforts on other conditions such as generalized anxiety disorder and substance use, patient samples were not large enough to do meaningful analyses. A composite outcome measuring delivery of integrated, whole-person care is needed to move beyond focusing on single-disease models, and this is an area for future research. Fifth, data on CMHCs included in our study are limited by small sample sizes, and therefore findings should be interpreted with caution. However, we included CMHCs in our study because integration is happening in both the primary care and CMHC settings in the United States, and the unique insight they provide into integration efforts in CMHCs warrants their inclusion. Finally, we do not have information on the percentage of patients who interacted with the integrated team. However, we included in Table 2 the percentage of patients who received integrated services from among those who screened positive over a 3 -month period. ${ }^{23}$

This study makes an important contribution to translational T3 research, which focuses on exploring ways of applying recommendations, guidelines, or approaches to care in general practice and yields knowledge about how interventions work in community settings. ${ }^{49}$ ACT accomplished this by creating an innovation incubator for practices focused on locally adapting and implementing approaches to integrate whole-person care. Through collaboratives and evaluation, ACT practices, program leaders, and evaluators came together to learn from each other. The products of that partnership resulted in both practical knowledge for how integration can be implemented in community settings and evidence that these efforts have a positive impact on patients.

This study provides evidence that when primary care-behavioral health integration approaches were translated to fit into community practices, they reduced depression severity and was perceived by patients as beneficial. Patients liked having behavioral and medical care under 1 roof; they appreciated that different members of their care team worked together, they reported feeling the positive effects of integration after only a few visits, and their outcomes improved. Findings from this study, together with a robust body of evidence from randomized controlled trials, makes a compelling case for practices to adopt integrated care and for payers to make this model feasible through finance reform.

To see this article online, please go to: http://jabfm.org/content/ 30/2/130.full.

\section{References}

1. Starfield B, Shi L, Macinko J. Contribution of primary care to health systems and health. Milbank Q 2005;83:457-502.

2. Collins C, Levis Hewson D, Munger R, Wade T. Evolving models of behavioral health integration in primary care. New York: Milbank Memorial Fund; 2010.

3. Miller BF, Petterson S, Brown Levey SM, PayneMurphy JC, Moore M, Bazemore A. Primary care, behavioral health, provider colocation, and rurality. J Am Board Fam Med 2014;27:367-74.

4. Croghan TW, Brown JD. Integrating mental health treatment into the patient-centered medical home. Rockville, MD: Agency for Healthcare Research and Quality, Mathematica Policy Research; 2010.

5. Gallo JJ, Zubritsky C, Maxwell J, et al. Primary care clinicians evaluate integrated and referral models of behavioral health care for older adults: results from a multisite effectiveness trial (PRISM-e). Ann Fam Med 2004;2:305-9.

6. Katon W, Unutzer J, Fan MY, et al. Cost-effectiveness and net benefit of enhanced treatment of depression for older adults with diabetes and depression. Diabetes Care 2006;29:265-70.

7. Unützer J, Katon WJ, Fan M-Y, et al. Long-term cost effects of collaborative care for late-life depression. Am J Manag Care 2008;14:95-100.

8. Chen H, Coakley EH, Cheal K, et al. Satisfaction with mental health services in older primary care 
patients. Am J Geriatr Psychiatry 2006;14: 371-9.

9. Unützer J, Katon W, Callahan CM, et al. Collaborative care management of late-life depression in the primary care setting: a randomized controlled trial. JAMA 2002;288:2836-45.

10. Katon W, Von Korff M, Lin E, et al. Collaborative management to achieve treatment guidelines: impact on depression in primary care. JAMA 1995;273: 1026-31.

11. Katon W, Von Korff M, Lin E, et al. Stepped collaborative care for primary care patients with persistent symptoms of depression: a randomized trial. Arch Gen Psychiatry 1999;56:1109-15.

12. Peek CJ. National Integration Academy Council lexicon for behavioral health and primary care integration: concepts and definitions developed by expert consensus. Rockville, MD: Agency for Healthcare Research and Quality; 2013.

13. Butler M, Kane RL, McAlpin D, et al. Integration of mental health/substance abuse and primary care. Evidence report/technology assessment no. 173. Rockville, MD: Agency for Healthcare Research and Quality; 2008.

14. Institute of Medicine. Crossing the quality chasm: a new health system for the 21 st century. Washington, DC: National Academies Press; 2001.

15. Cohen DJ, Balasubramanian BA, Davis M, et al. Understanding care integration from the ground up: five organizing constructs that shape integrated practices. J Am Board Fam Med 2015;28(Suppl 1):S7-20.

16. Green LA, Cifuentes M. Advancing care together by integrating primary care and behavioral health. J Am Board Fam Med 2015;28(Suppl 1):S1-6.

17. Kathol RG, Degruy F, Rollman BL. Value-based financially sustainable behavioral health components in patient-centered medical homes. Ann Fam Med 2014;12:172-5.

18. Cohen DJ, Davis M, Balasubramanian BA, et al. Integrating behavioral health and primary care: consulting, coordinating and collaborating among professionals. J Am Board Fam Med 2015;28(Suppl 1): S21-31.

19. Davis MM, Balasubramanian BA, Cifuentes M, et al. Clinician staffing, scheduling, and engagement strategies among primary care practices delivering integrated care. J Am Board Fam Med 2015;28(Suppl 1):S32-40.

20. Hall J, Cohen DJ, Davis M, et al. Preparing the workforce for behavioral health and primary care integration. J Am Board Fam Med 2015;28(Suppl 1):S41-51.

21. Gunn R, Davis MM, Hall J, et al. Designing clinical space for the delivery of integrated behavioral health and primary care. J Am Board Fam Med 2015; 28(Suppl 1):S52-62.

22. Cifuentes M, Davis M, Fernald D, Gunn R, Dickinson P, Cohen DJ. Electronic health record chal- lenges, workarounds, and solutions observed in practices integrating behavioral health and primary care. J Am Board Fam Med 2015;28(Suppl 1):S63-72.

23. Balasubramanian BA, Fernald D, Dickinson LM, et al. REACH of interventions integrating primary care and behavioral health. J Am Board Fam Med 2015; 28(Suppl 1):S73-85.

24. Wallace NT, Cohen DJ, Gunn R, et al. Start-up and ongoing practice expenses of behavioral health and primary care integration interventions in the advancing Care Together (ACT) program. J Am Board Fam Med 2015;28(Suppl 1):S86-97.

25. Miller BF. When frontline practice innovations are ahead of the health policy community: the example of behavioral health and primary care integration. J Am Board Fam Med 2015;28(Suppl 1):S98-101.

26. Dickinson WP. Strategies to support the integration of behavioral health and primary care: what have we learned thus far? J Am Board Fam Med 2015; 28(Suppl 1):S102-6.

27. deGruy FV 3rd. Integrated care: tools, maps, and leadership. J Am Board Fam Med 2015;28(Suppl 1):S107-10.

28. Cohen DJ, Davis M, Balasubramanian BA, et al. Integrating behavioral health and primary care: Consulting, coordinating, and collaborating among professionals. J Am Board Fam Med 2015;28(Suppl 1):S21-S31.

29. Wallace N, Cohen DJ, Gunn R, et al. Start-up and ongoing practice expenses of behavioral health and primary care integration interventions in the Advancing Care Together (ACT) program. J Am Board Fam Med 2015; 28(Suppl 1):S86-97.

30. Balasubramanian BA, Cohen DJ, Davis MM, et al. Learning evaluation: blending quality improvement and implementation research methods to study healthcare innovations. Implement Sci 2015; $10: 31$.

31. Kroenke K, Spitzer RL, Williams JB. The PHQ-9: validity of a brief depression severity measure. J Gen Intern Med 2001;16:606-13.

32. Fetters MD, Curry LA, Creswell JW. Achieving integration in mixed methods designs-principles and practices. Health Serv Res 2013;48(6 Pt 2):2134-56.

33. Kroenke K, Spitzer RL, Williams JB. The PHQ-15: validity of a new measure for evaluating the severity of somatic symptoms. Psychosom Med 2002;64: 258-66.

34. Kroenke K, Strine TW, Spitzer RL, Williams JB, Berry JT, Mokdad AH. The PHQ-8 as a measure of current depression in the general population. J Affect Disord 2009;114:163-73.

35. Laird NM, Ware JH. Random-effects models for longitudinal data. Biometrics 1982;38:963-74.

36. Bradley EH, Curry LA, Devers KJ. Qualitative data analysis for health services research: developing taxonomy, themes, and theory. Health Serv Res 2007; 42:1758-72. 
37. Borkan J. Immersion/crystallization. In: Crabtree BF, Miller WL, eds. Doing qualitative research. Thousand Oaks, CA: Sage Publications; 1999:179-94.

38. Cohen DJ, Crabtree BF, Etz RS, et al. Fidelity versus flexibility: translating evidence-based research into practice. Am J Prev Med 2008;35(5 Suppl): S381-9.

39. Cohen DJ, Crabtree BF. Evaluative criteria for qualitative research in health care: controversies and recommendations. Ann Fam Med 2008;6:331-9.

40. Creswell JW, Fetters MD, Ivankova NV. Designing a mixed methods study in primary care. Ann Fam Med 2004;2:7-12.

41. Bogner HR, Morales KH, de Vries HF, Cappola AR. Integrated management of type 2 diabetes mellitus and depression treatment to improve medication adherence: a randomized controlled trial. Ann Fam Med 2012;10:15-22.

42. Kravitz RL, Franks P, Feldman MD, et al. Patient engagement programs for recognition and initial treatment of depression in primary care: a randomized trial. JAMA 2013;310:1818-28.

43. Mohr DC, Duffecy J, Ho J, et al. A randomized controlled trial evaluating a manualized TeleCoaching protocol for improving adherence to a web-based in- tervention for the treatment of depression. PLoS One 2013;8:e70086.

44. Bogner HR, de Vries HF, Kaye EM, Morales KH. Pilot trial of a licensed practical nurse intervention for hypertension and depression. Fam Med 2013;45: 323-9.

45. Alexopoulos GS, Reynolds CF 3rd, Bruce ML, et al. Reducing suicidal ideation and depression in older primary care patients: 24-month outcomes of the PROSPECT study. Am J Psychiatry 2009; 166:882-90.

46. Kessler D, Lewis G, Kaur S, et al. Therapist-delivered Internet psychotherapy for depression in primary care: a randomised controlled trial. Lancet 2009;374:628-34.

47. O'Connor EA, Whitlock EP, Beil TL, Gaynes BN. Screening for depression in adult patients in primary care settings: a systematic evidence review. Ann Intern Med 2009;151:793-803.

48. Unützer J, Park M. Strategies to improve the management of depression in primary care. Prim Care 2012;39:415-31.

49. Woolf SH. The meaning of translational research and why it matters. JAMA 2008;299:211-3. 